\title{
Andrea Ciarmiello and Luigi Mansi (eds): PET/CT and PET/MRI in neurology. SWOT analysis applied to hybrid imaging
}

\author{
Springer International Publishing Switzerland, 2016, (ISBN: 978-3-319-31612-3)
}

\author{
Georges El Fakhri ${ }^{1}$
}

Published online: 4 February 2017

(C) Springer-Verlag Berlin Heidelberg 2017

The editors of this monograph are Andrea Ciarmiello, Professor of Nuclear Medicine at the Department of Nuclear Medicine, S. Andrea Hospital of La Spezia, and Luigi Mansi, Professor of Nuclear Medicine at the Department of Nuclear Medicine, Second University of Naples, Italy. The book applies SWOT analysis to the evaluation of the strengths, weaknesses, opportunities and threats of hybrid methods. The rationale for using this analytical approach to neurological decision making is related to the need to avoid the risk of wasting any diagnostic opportunity provided by research and implementation. Great effort has been made to present the discussion of this very specialized material in a manner accessible not only to experts in the field but also to neophytes.

The book is structured into 20 chapters totalling 319 pages including many images and tables. In the first five chapters, the authors describe in detail the basics of hybrid imaging. The main body of the book, comprising the second and third parts, focuses on clinical applications of hybrid imaging in neurology, with regard to the incidence of disease. This structure is very convenient for addressing the utility of the hybrid imaging approach for each neurological disorder according to epidemiology.

Overall the chapters are of high quality and well written. Because this is a multiauthor book, although a standard format is substantially respected, there is some heterogeneity in the structure and the content of some chapters. The general level is very good but, although some chapters are very original and reflect the state of the art, others could probably be improved. Nevertheless, this is definitely a book worth owning as a reference volume for the topic.

The book is mainly addressed to neurologists but also to students, and other clinical specialists. We recommend this book to neurologists, nuclear physicians, radiologists and residents interested in the topic.
Georges El Fakhri

elfakhri@pet.mgh.harvard.edu

1 Massachusetts General Hospital, Boston, MA 02114, USA 